\title{
Acute effects of 2D exergame on cognitive functions and frontal cortical activity
}

\author{
Efeitos agudos do exergame 2D nas funções cognitivas e na atividade do córtex frontal \\ Efectos agudos del exergame $2 \mathrm{D}$ sobre las funciones cognitivas y la actividad cortical frontal
}

\author{
Osmano Tavares de Souza ${ }^{a}$ (D), Frederico Sander Mansur Machado ${ }^{b}$ (i), \\ Lara Sofia Rodrigues de Sousa Fernandes Carneiro ${ }^{c}$ (D) , Vinicius Dias Rodrigues ${ }^{d}$ (D), \\ Carla Silvana de Oliveira e Silva ${ }^{a}$ (D) , Luana Lemos Leão ${ }^{b}$ (D), \\ Renato Sobral Monteiro-Junior ${ }^{a^{*}}$ (D)
}

\section{Keywords:}

Physical activity;

Cognition;

Video game;

Cerebral cortex.

Palavras-chave: Atividade física; Cognição; Vídeo game; Córtex Cerebral.

Palabras clave: Actividad física; Cognición; Video game; Corteza cerebral.

\begin{abstract}
This study aims to evaluate the effect of an exercise with a 2D virtual reality session on the cognition and cortical activity of young males. This is a randomized controlled trial with ten men aged 18 to 23 years. They were randomly assigned under two conditions: 1) exercise session with 2D virtual reality games and 2) control, which consisted of watching a two-episode video of a comic TV show. Cognition and frontal cortical activity were assessed immediately before and after the intervention, using the Mindset, performing the Digit Span Test, semantic verbal fluency, and executive function. Executive function improved with the exergame session $(p=0.025)$. Exergames partially promote an immediate increase in the executive function of young people.
\end{abstract}

\section{RESUMO}

Este estudo tem como objetivo avaliar o efeito de um exercício com sessão de realidade virtual 2D na cognição e atividade cortical de jovens do sexo masculino. Trata-se de um ensaio controlado randomizado com dez homens de 18 a 23 anos. Os participantes foram distribuídos aleatoriamente em duas condições: 1) sessão de exercícios com jogos de realidade virtual 2D e 2) controle, que consistia em assistir a um vídeo de dois episódios de um programa de TV. A cognição e a atividade cortical frontal foram avaliadas imediatamente antes e após a intervenção, por meio do Mindset, realização do Digit Span Test, fluência verbal e função executiva. A função executiva melhorou com a sessão de exergame $(p=0,025)$. Exergames promove parcialmente um aumento imediato na função executiva dos jovens.

\section{RESUMEN}

Este estudio tiene como objetivo evaluar el efecto de un ejercicio con sesión de realidad virtual 2D sobre la cognición y la actividad cortical de varones jóvenes. Este es un ensayo controlado aleatorio con diez hombres de 18 a 23 años. Fueron asignados aleatoriamente bajo dos condiciones: 1) sesión de ejercicios con juegos de realidad virtual 2D y 2) control, que consistía en ver dos episodios de un programa de televisión. Se evaluó la cognición y la actividad cortical frontal inmediatamente antes y después de la intervención, utilizando el Mindset, realizando el Digit Span Test, la fluidez verbal y la función ejecutiva. La función ejecutiva mejoró con la sesión de exergame $(p=0.025)$. Exergames promueven parcialmente un aumento de la función ejecutiva de los jóvenes.

\footnotetext{
anniversidade Estadual de Montes Claros. Montes Claros, MG, Brasil.

bUniversidade Estadual de Montes Claros. Programa de Pós-graduação em Ciências da Saúde. Montes Claros, MG, Brasil. 'Universidade da Maia. Maia, Portugal.

¿Universidade Estadual de Montes Claros. Departamento de Educação Física e do Desporto. Montes Claros, MG, Brasil.
}

*Corresponding author:

Renato Sobral Monteiro-Junior

E-mail: monteirojuniorms@gmail.com 


\section{INTRODUCTION}

Active games -or exergames combine physical exercises and videogames to require the whole body to move (Lin, 2015). Exergames tasks raise blood pressure, heart rate, oxygen consumption, and energy expenditure, which can promote several physiological adaptations (Garber et al., 2011; Peng et al., 2011; Lau et al., 2016; Zeng et al., 2017). On the other hand, cognitive adaptations occur due to double-task stimuli, motor and cognitive, thus demanding the integration of cognitive functions to interact with the virtual environment through body movement. Moreover, this association between motor and cognitive functions would be crucial to the understanding of the adaptive processes resulting from this hybrid form of physical training.

Hwang and Lu (2018) in their study evaluating the effects of narrative exergames on cognition and physical activity, recruited 100 healthy young men and women, aged 18 to 25 years old. The study involved different types of games, one with active exergames and the nonactive, the intervention lasted $30 \mathrm{~min}$, and evaluated the working memory and sustained attention, such functions required by the prefrontal cortex, posterior orbitofrontal regions, hippocampus, and frontal cortical regions, and posterior parietal cortex, respectively. The results showed that young people trained with active exergame had a better performance in the cognitive task, dependent on the prefrontal cortex.

Due to the contrast of the results and insubstantial data, the dynamics of cortical activity and the cognitive responses to exergames are still being debated (Hwang and Lu, 2018). There is no consensus on the use of this intervention, mainly using the Nintendo Wii tool, to observe its effects in an acute way to improve youngsters' cognitive responses. Besides, the neurophysiological mechanisms are not fully understood. Therefore, this study aimed to assess the effect of an exercise session with exergames on the modulation of the frontal cortical activity and on the young males' cognitive functions.

\section{METHOD}

\section{STUDY DESIGN}

This was a study characterized as a simple crossover study (Dwan et al., 2019). Participants were submitted randomly to an acute and control intervention.

\section{SAMPLE}

The study included 10 academic males attending the course of Physical Education, age between 18 and 23 years, from the State University of Montes Claros. We used simple random sampling, and the participants were selected by convenience (according to the availability of participants). The inclusion criteria were being $\geq 18$ years old and fit to perform physical effort, meeting the Pre- Exercise Screening Questionnaire of the American
Heart Association (Balady et al., 1998); and exclusion criteria were no neurodegenerative diseases and musculoskeletal injury that might hinder the intervention and the testing performance; and use of any medicine or food supplement.

Participants attended the Laboratory of the Group of Studies and Research in Neuroscience, Exercise, Health, and Sport (GENESEs) to perform the intervention according to previous reservation and availability. Participants signed the informed written consent about the research protocol, which has been approved by the Research Ethics Committee of State University of Montes Claros under the protocol 3037415/2018. CAAE: 01999318.3.0000.5146.

\section{EVALUATIONS APPLIED IN THE STUDY}

\section{ANTHROPOMETRY}

We used bioimpedance to assess volunteers' height and body composition before the intervention. Data collection met the criteria by Bosy-Westphal et al. (2013) with the demanding pre-physical assessment. Assessments were conducted on the right side of the body, with the participant lying down on a nonconducting surface.

\section{CORTICAL ACTIVITY}

Cortical activity assessment was performed through a brain-smartphone interface using the Mindset ${ }^{\mathrm{TM}}$ (NeuroSky, San Jose, California, USA). The device contains a stainless-steel electrode (FP1 - reference of international system 10/20) with $10 \mathrm{~mm}$ diameter and an earth electrode positioned on the participant's left ear lobe. Electric power is obtained and amplified 8000 times. Data sampling $(128 \mathrm{~Hz})$, filtering, and analogical to digital signal conversion are modulated by an inner microchip (ThinkGear) that analyses data through a Fourier Transform and obtains the power of Delta $(0-3 \mathrm{~Hz})$, Theta (4-7 Hz), Alpha (8-12 Hz), Beta (13-30 Hz) and Gamma (>30 Hz) frequency bands (Yasui, 2009; Rogers et al., 2016). Data were transmitted via Bluetooth to the app eegID ${ }^{\text {TM }}$ (Isomer Programming LLC, Hampton, Virginia, USA) downloaded to a cellphone Moto $5^{\text {TM }}$ (Motorola, Illinois, USA). Cortical activity was obtained at repose and during cognitive assessments (short-term Platform and working memory and semantic verbal fluency/executive function). In each assessment, the signal was captured for 5 min. To avoid constraints, participants were guided to remain seated, eyes shut, and without moving during signal capture. The variable used for analysis was the relative power of frequency bands, obtained through the division of absolute power of each band by the sum of the absolute power of all bands and multiplied by 100 . Data collection reliability with Mindset ${ }^{\mathrm{TM}}$ is acceptable (Intraclass Coefficient Correlation $=0.76-0.85$ ) when the assessment is conducted with the individual with eyes shut (Rogers et al., 2016). 


\section{SHORT TERM MEMORY AND WORKING MEMORY}

We used the Digit Span Test, which is divided into two parts. In the first part, upon command, the participant should repeat orally the numerical sequence maintaining the order presented (Digit Span Forward). During the second part, the participants must repeat the numerical sequence inversely to the order that it has been presented (Digit Span Backwards) This part demands memory and the ability of reversibility (working memory), which can be summed up by the ability to store information for short periods and to manipulate it through basic coding, maintenance, and recovery operations (Schroeder et al., 2012).

\section{SEMANTIC VERBAL FLUENCY AND EXECUTIVE FUNCTION}

We used the Verbal Fluency Test. The participants were guided to utter the highest number of animals/ people/fruits for 60 seconds each, totaling 3 blocks of one min in each category. The final score is the total number of answers remembered by the participant in each category (Brucki et al., 1997; Jurado and Rosselli, 2007).

\section{INTERVENTION SESSION}

Participants performed an exergame session (experimental and familiarization sessions) with the Nintendo Wii (Kyoto, Japan) for 30-45 minutes. The following games were used: Platform Plus, City Swinging, Snowballs, Big Top Juggling and Get a 10 . The games were administered again in the experimental session in a week other than familiarization for 30-45 minutes. The games played can be seen at Nintendo (2021). These activities have been selected as they demanded simultaneously cognitive and physical skills during practice (Tahmosybayat et al., 2018). Thus, as randomization 4 members started in the experimental condition and 6

Table 1. Sample characteristics.

\begin{tabular}{lcc}
\hline & Mean & SD \\
\hline Age (years) & 20.2 & 1.4 \\
Weight $(\mathrm{kg})$ & 70.18 & 13.56 \\
Height $(\mathrm{m})$ & 1.75 & 0.08 \\
BMI $\left(\mathrm{kg} / \mathrm{m}^{2}\right)$ & 23.05 & 3.85 \\
Basal Metabolism (kcal) & 1856.50 & 253.03 \\
\hline
\end{tabular}

SD: standard deviation; BMI: body mass index. members in the control condition, all went through both conditions of the intervention. Therefore, during the experimental session, participants were guided to climb onto the Platform Wii Balance Board to start exergames sessions. They performed each activity 3 times, with intervals (20 to $35 \mathrm{~s}$ ) of rest in the standing position, sufficient for the game change. Participants were verbally stimulated to improve the score each time they played the same game. Before and after the exergames session, the frontal cortical activity was assessed during the shortterm memory testing, as well as the working memory and the semantic verbal fluency/ executive function, all tests were explained to the participants before starting.

The control group participants were guided to sit down on a chair in front of a notebook that displayed a two-episode video of a comic TV show lasting the same time as the experimental session. The video was chosen because it stimulates visual attention, and because it has characteristics that are not boring since it was exercised through games (highly interactive), but without physical stimuli. The experimental and control evaluations were carried out on different days with an interval of 2-3 days between them. After the control group assessment, carried out equally as in the experimental condition, the participants' cortical activity was assessed during the same cognitive tests mentioned above.

\section{DATA ANALYSIS}

The Shapiro-Wilk and Levene tests were used to verify data normality and homoscedasticity, respectively. Descriptive analyses were used for sample characterization and result presentation. Differences between post and pre-intervention data $(\Delta)$ were estimated. Dependent T-Test was used in the parametric analyses, while the Wilcoxon test was applied to the non-parametric analyses. The significance level was considered $\leq 0.05$. The data were analyzed in software R.

\section{RESULTS}

Table 1 shows sample characteristics. There was no statistical difference in any brain waves in any assessment $(p>0.05)$. Therefore, no significant cortical alterations were found in the left frontal lobe (Table 2).

Table 3 shows that the exergames session increased verbal fluency on the "fruits" category $(p=0.025)$. Furthermore, the answers to the other categories and the other tests have not been changed by exergames.

Table 2. Result of the relative power of brain waves during exergame (EXG) and control (CT) (post-intervention minus pre-intervention).

\begin{tabular}{|c|c|c|c|c|c|c|c|c|}
\hline \multirow{2}{*}{ Brain Waves } & \multicolumn{3}{|c|}{ Rest } & \multicolumn{5}{|c|}{ During Cognitive Tests } \\
\hline & CT & EXG & $t / z$ & P-value & CT & EXG & $t / z$ & P-value \\
\hline Delta $_{(\%)}$ & $0.03(0.13)$ & $-0.04(0.08)$ & -1.4 & $0.174^{\#}$ & $0.00(0.80)$ & $-0.01(0.07)$ & -0.46 & $0.651^{\#}$ \\
\hline Theta ${ }_{(\%)}$ & $-0.03(0.09)$ & $0.02(0.07)$ & 0.58 & $0.576^{\#}$ & $0.00(0.09)$ & $-0.01(0.05)$ & -0.37 & $0.718^{\#}$ \\
\hline Alpha & $-0.01(0.03)$ & $-0.02(0.09)$ & -0.27 & $0.792^{\#}$ & $-0.21(0.08)$ & $-0.09(0.08)$ & -0.96 & $0.333^{*}$ \\
\hline Beta $(\%)$ & $0.03(0.12)$ & $0.03(0.05)$ & -0.08 & $0.933^{\#}$ & $-1.2(0.10)$ & $-0.04(0.06)$ & -0.35 & $0.721^{*}$ \\
\hline
\end{tabular}


Table 3. The difference in cognitive functions (post-intervention minus pre-intervention) in response to exergame sessions.

\begin{tabular}{ccccc}
\hline \multirow{2}{*}{ Tests } & \multicolumn{2}{c}{ M (SD) M (SD) } & t & P-Value \\
\cline { 2 - 4 } & EXGs & CT & 1.03 & 0.331 \\
Flu/A & $5(4.71)$ & $5(6.00)$ & -0.87 & 0.409 \\
$\mathrm{Flu} /$ (score) $_{\text {(score) }}$ & $2(5.22)$ & $1(3.46)$ & 2.68 & $\mathbf{0 . 0 2 5}$ \\
$\mathrm{Flu} / \mathrm{F}_{\text {(score) }}$ & $4(3.26)$ & $1(2.06)$ & 0.46 & 0.654 \\
DSF $_{\text {(score) }}$ & $1.5(2.02)$ & $0.5(1.2)$ & -0.17 & 0.868 \\
DSB $_{\text {(score) }}$ & $0(1.35)$ & & \\
\hline
\end{tabular}

M: Mean; SD standard deviation; Flu/A: Animal Verbal Fluency; Flu/P: People Verbal Fluency; Flu/F: Fruit Verbal Fluency; DSF: Digit Span Forward; DSB: Digit Span Backward. t: t-test result; P-value $\leq 0.05$ is statistically significant.

Table 4. Wii Fit Plus games and the brain area with predominant activation.

\begin{tabular}{ll}
\hline Wii Fit Plus Games \\
\hline Plataforma Plus 10 & $\begin{array}{l}\text { Games with a predominance of } \\
\text { demanding executive functions, } \\
\text { specifically the prefrontal cortex. } \\
\text { prefrontal cortex }\end{array}$ \\
Circus juggling & \\
Snowballs & \\
City Swinging
\end{tabular}

Table 4 shows the brain area with predominant activation due to the intervention.

\section{DISCUSSION}

This study evaluated the effect of exergames on the left frontal cortical activity and cognitive functions of young adults to observe the relationship between the executive function and the neurophysiological response after an exergame exercise session. One of the categories of the verbal fluency/executive function score increased after exergame, regardless of the significant cortical alterations on the left frontal lobe.

Oei and Patterson (2013), who have shown that different games with distinct cognitive demands (attention, spatial memory, and double task) have improved participants' executive function, irrespective of the alterations in the cortical activity. On the other hand, Anders et al. (2018), who used exergames with 24 young people, have shown that participants improved cognition together with significant brain wave alterations, increasing the activity in alpha- 2 on the central area of the right and left parietal cortex, besides the increasing on the theta wave in the central area of the frontal cortex. Additionally, the study conducted the cognitive assessment with the participants with eyes-open and with a 64-channel EEG, different from our investigation, since we assessed participants with eyes-closed and with one electrode EEG that evaluates electrical activity on the left prefrontal cortex, which might partially explain the difference in the findings. Nouchi et al. (2013) investigated the impact of two exergames in 32 young adults and have shown that the participants' working memory and velocity of processing improved, hence corroborating with our findings that exhibited an improvement of the individual's executive function.

Palaus et al. (2017) have shown that the videogame training promoted structural changes in the gray matter and raised the volume of the hippocampus, cerebellum, and prefrontal regions, mainly in the dorsolateral prefrontal cortex and adjacent areas, besides the parietal lobe. These findings can be associated with the enhancement of attention, visual-spatial abilities, and reward processing. Basak et al. (2011) have also shown structural changes on the medial frontal gyrus, postcentral gyrus, dorsolateral prefrontal cortex, and cerebellum, in healthy elderly who performed $23.5 \mathrm{~h}$ of virtual reality games. Other studies confirm that videogame impact executive function (Rivero et al., 2012; Stanmore et al., 2017).

The acute alteration of the executive change found in our study has shown that exergames have the potential to a fast-cognitive stimulation, possibly pleasant, and might be applied to young adults to ease task commitment that requires planning, judgment, and problem-solving. In line with these findings, we could suppose that 30-45 min of exergames performed before the main task, which requires the executive function, might soften an individual's performance, e.g., a logical reasoning test or even sports activities.

Although our study does not show significant cortical changes, it presents a finding that might motivate investigators to conduct research with bigger casuistry to better understand the dose-response of necessary sessions to cause cognitive alterations compatible with meaningful cortical changes, besides the use of other neurophysiological analysis instruments. Furthermore, small changes in verbal fluency (e.g., two words), as shown in our study, could modify an individual's classification (scores $<13$ points represent cognitive impairment). 
Despite an increase in executive function, our study presents important limitations. The equipment used to capture brain waves allows only a power analysis of left frontal lobe time, hence, not enabling to observe changes in other areas of the cerebral cortex. In addition, we have assessed just one exergame session, which allows us only short-term inferences and the failure to perform a sample calculation for study. Further investigations should be conducted with more time, with an experimental design, and with more sophisticated equipment to observe in detail the neurophysiological phenomena of virtual games, in addition to performing with a significant number of participants through the sample calculation. On the other hand, this study has used low-cost and easily operated equipment, which furthers investigations that aim to assess only the electric activity on the left frontal cortex.

\section{CONCLUSION}

Exergames partially promote an immediate increase in the executive function of young people. This change appears to be relatively independent of changes in left frontal cortical activity.

\section{FUNDING}

This research received no specific grant from any funding agency in the public, commercial, or not-forprofit sectors.

\section{CONFLICTS OF INTEREST}

The authors have no conflicts of interest to declare.

\section{ACKNOWLEDGEMENTS}

We thank the Research and Study Group of Neuroscience, Exercise, Health, and Sport (GENESEs Unimontes).

\section{REFERENCES}

Anders P, Lehmann T, Müller H, Grønvik KB, Skjæret-Maroni N, Baumeister J, et al. Exergames inherently contain cognitive elements as indicated by cortical processing. Front Behav Neurosci. 2018;12:102. http://dx.doi.org/10.3389/ fnbeh.2018.00102. PMid:29867400.

Balady GJ, Chaitman B, Driscoll D, Foster C, Froelicher E, Gordon N, et al. Recommendations for cardiovascular screening, staffing, and emergency policies at health/ fitness facilities. Circulation. 1998;97(22):2283-93. http:// dx.doi.org/10.1161/01.CIR.97.22.2283. PMid:9631884.

Basak C, Voss MW, Erickson KI, Boot WR, Kramer AF. Regional differences in brain volume predict the acquisition of skill in a complex real-time strategy videogame. Brain Cogn. 2011;76(3):407-14. http://dx.doi.org/10.1016/j. bandc.2011.03.017. PMid:21546146.

Bosy-Westphal A, Schautz B, Later W, Kehayias JJ, Gallagher D, Müller MJ. What makes a BIA equation unique? Validity of eight-electrode multifrequency BIA to estimate body composition in a healthy adult population. Eur J Clin Nutr. 2013;67:S14-S21. http://dx.doi.org/10.1038/ ejcn.2012.160.

Brucki SM, Malheiros SM, Okamoto IH, Bertolucci PH. Dados normativos para o teste de fluência verbal categoria animais em nosso meio. Arq Neuropsiquiatr. 1997;55(1):56-61. http://dx.doi.org/10.1590/S0004282X1997000100009. PMid:9332561.

Dwan K, Li T, Altman DG, Elbourne D. CONSORT 2010 statement: extension to randomised crossover trials. BMJ. 2019;366:|4378. http://dx.doi.org/10.1136/bmj.14378.

Garber CE, Blissmer B, Deschenes MR, Franklin BA, Lamonte MJ, Lee IM, et al. American College of Sports Medicine position stand. Quantity and quality of exercise for developing and maintaining cardiorespiratory, musculoskeletal, and neuromotor fitness in apparently healthy adults: guidance for prescribing exercise. Med Sci Sports Exerc. 2011;43(7):1334-59. http://dx.doi.org/10.1249/ MSS.0b013e318213fefb. PMid:21694556.

Hwang J, Lu AS. Narrative and active video game in separate and additive effects of physical activity and cognitive function among young adults. Sci Rep. 2018;8(1):11020. http:// dx.doi.org/10.1038/s41598-018-29274-0. PMid:30030456.

Jurado MB, Rosselli M. The elusive nature of executive functions: a review of our current understanding. Neuropsychol Rev. 2007;17(3):213-33. http://dx.doi. org/10.1007/s11065-007-9040-z. PMid:17786559.

Lau PW, Wang JJ, Maddison R. A Randomized-controlled trial of school-based active videogame intervention on chinese children's aerobic fitness, physical activity level, and psychological correlates. Games Health J. 2016;5(6):40512. http://dx.doi.org/10.1089/g4h.2016.0057. PMid:27855265.

Lin JH. "Just Dance": the effects of exergame feedback and controller use on physical activity and psychological outcomes. Games Health J. 2015;4(3):183-9. http://dx.doi. org/10.1089/g4h.2014.0092. PMid:26182062.

Nintendo. Wii Fit [cited 2019 May 20]. 2021. Available from: https://www.nintendo.co.uk/Games/Wii/Wii-Fit-283894. html

Nouchi R, Taki Y, Takeuchi H, Hashizume H, Nozawa T, Kambara $\mathrm{T}$, et al. Brain training game boosts executive functions, working memory and processing speed in the young adults: a randomized controlled trial. PLoS One. 2013;8(2):e55518. http://dx.doi.org/10.1371/journal. pone.0055518. PMid:23405164.

Oei AC, Patterson MD. Enhancing cognition with video games: a multiple game training study. PLoS One. 2013;8(3):e58546. http://dx.doi.org/10.1371/journal.pone.0058546. PMid:23516504.

Palaus M, Marron EM, Viejo-Sobera R, Redolar-Ripoll D. Neural basis of video gaming: a systematic review. Front Hum Neurosci. 2017;11:248. http://dx.doi.org/10.3389/ fnhum.2017.00248. PMid:28588464.

Peng W, Lin JH, Crouse J. Is playing exergames really exercising? A meta-analysis of energy expenditure in active video games. Cyberpsychol Behav Soc Netw. 2011;14(11):681-8. http:// dx.doi.org/10.1089/cyber.2010.0578. PMid:21668370. 
Rivero TS, Querino EHG, Starling-Alves I. Videogame: seu impacto na atenção, percepção e funções executivas. Neuropsicol Latinoam. 2012;4:38-52.

Rogers, J. M., Johnstone, S. J., Aminov, A., Donnelly, J., \& Wilson, P. H. Test-retest reliability of a single-channel, wireless EEG system. Int J Psychophysiol. 2016;106:87-96. https://doi. org/10.1016/j.ijpsycho.2016.06.006.

Schroeder RW, Twumasi-Ankrah P, Baade LE, Marshall PS. Reliable Digit Span: a systematic review and crossvalidation study. Assessment. 2012;19(1):21-30. http:// dx.doi.org/10.1177/1073191111428764. PMid:22156721.

Stanmore E, Stubbs B, Vancampfort D, de Bruin ED, Firth J. The effect of active video games on cognitive functioning in clinical and non-clinical populations: a meta-analysis of randomized controlled trials. Neurosci Biobehav
Rev. 2017;78:34-43. http://dx.doi.org/10.1016/j. neubiorev.2017.04.011. PMid:28442405.

Tahmosybayat R, Baker K, Godfrey A, Caplan N, Barry G. Movements of older adults during exergaming interventions that are associated with the Systems Framework for Postural Control: a systematic review. Maturitas. 2018;111:90-9. http://dx.doi.org/10.1016/j. maturitas.2018.03.005. PMid:29673837.

Yasui Y. A brainwave signal measurement and data processing technique for daily life applications. J Physiol Anthropol. 2009;28(3):145-50. http://dx.doi.org/10.2114/ jpa2.28.145. PMid:19483376.

Zeng N, Pope Z, Lee JE, Gao Z. A systematic review of active video games on rehabilitative outcomes among older patients. J Sport Health Sci. 2017;6(1):33-43. http://dx.doi. org/10.1016/j.jshs.2016.12.002. PMid:30356538. 